\title{
EDITORIAL
}

\section{EI Nino - A short term signal of a long term and a large scale climate variation}

Man has lived in harmony with nature adapting to its changes. Science has enabled him to get a better understanding of nature and how it behaves. Scientists have studied how and why changes take place in natural phenomena such as weather and climate. Based on the results we have further adapted to the environment around us.

Until recent times, meteorologists studied only the atmosphere while oceanographers studied the oceans. Scientists have now realized that the atmosphere and the oceans need to be studied together as their behaviour is coupled. It is now well established that weather and climate variations are influenced by oceanic phenomena. El Nino is such an oceanic event occurring in the Eastern Pacific. It causes atmospheric changes resulting in an unprecedented damage the world over. This led multidisciplinary teams of scientists to conduct detailed studies of the ocean especially the El Nino activity in the Pacific under a 10-year (1985-1994) research programme - Tropical Ocean and Global Atmosphere (TOGA) - in which scientists with multidisciplinary backgrounds from almost all countries of the world participated. This programme mainly focused on the largest tropical ocean (the Pacific) to study climate variability on seasonal to inter-annual time scale. Using data regarding surface winds, sea surface temperature, upper ocean heat content, surface currents and sea level, scientists discovered many facts on physical processes related to El Nino that influence short-term climate variability.

On the global scale, the atmospheric surface pressure is low over the equatorial Western Pacific areas such as Australia, Indonesia and Sri Lanka and it is high over the Eastern Pacific. Associated with the pressure gradient across the Pacific from east to west are the easterly trade winds that prevail throughout the year. The wind stress over the ocean surface pushes warm surface water towards Western Pacific and a warm pool of water resides there. This phenomenon results in the Eastern Pacific remaining cold throughout the year. There are also other reasons such as large scale oceanic circulation of cold water from the high latitudes of the Southern hemisphere and the movement of cold water upwards due to the process of upwelling, for the water to be cold in this equatorial region. The temperature difference between the Eastern and the Western Pacific sometimes reaches $4^{\circ}$ Celsius.

Every year around December, associated with the seasonal changes, the waters off the coast of Peru become warmer. This annual phenomenon was called El Nino. Once in four to seven years the warming becomes strong and extends over a large area in the Eastern Pacific. At present the term El Nino is used to identify only those exceptional warm events rather than the annual occurrences. As a result of this warming and other biological and physical processes, the fishing industry in the area gets totally disrupted.

Oceanic variations influence both weather and climate. Under normal conditions, air rises upwards in the warm pool of the Western Pacific and sinks in the cold Eastern Pacific. This brings excessive rain to the Western Pacific (Australia, Indonesia, Malaysia, Thailand, China, Japan, extending towards India and Sri Lanka) especially during the monsoon periods. Simultaneously, the Eastern Pacific becomes an oceanic desert with no rain throughout the year. Usually, once in four to seven years, the normal pattern changes. Trade winds become weak and the warm water in the Western Pacific moves eastwards reaching the Central and Eastern Pacific around December. When this happens the Central and Eastern Pacific receive a substantial amount of rain, which is an abnormal condition for that region and the Western Pacific is affected by draught conditions. This is a complete reversal of the weather pattern over the region and is known as the El Nino Southern Oscillation (ENSO). This reversal is not limited to the Pacific region only but weather-wise the influence is felt globally in many ways. 
Historically there has been mild, moderate and strong El Nino events recorded. The 1982/83 event was a major El Nino event and it was considered the strongest in the century until 1997/98 event which was found to be even stronger. During these events the temperature gradient across the Pacific was over $4^{\circ}$ Celsius and the AustralAsian region as well as whole of India faced severe drought conditions for over 6 months.

The surface pressure is generally low in the Western Pacific and Eastern Indian oceans as compared to the equatorial Eastern Pacific. Therefore, air flows towards this region (India, Sri Lanka, Australia and Indonesia) throughout the year. The air that flows towards the low pressure area rises and produces clouds and rain. Sri Lanka experiences rainy weather accompanying thunderstorm activity during the on-set and tail-end of the monsoon periods.

During El Nino years the pressure is relatively high over this region, as compared to East Pacific. When the surface pressure is high, the winds tend to blow away from this area and dry air from the upper atmosphere sinks and this in turn prevents upward motion of the air, cloud formation and rainfall. Therefore, during El Nino, continuous dry weather is experienced in this region for a long period of time. However, the coupled system of atmosphere-ocean is very complex and the severity of the drought condition depends on the strength of El Nino signal and various other regional scale variations.

During a strong El Nino event, weather changes occur throughout the world. During the 1982/83 event, while some areas of the world experienced drought conditions, some other parts experienced the worst floods in history. The entire Asian monsoon region including India and Sri Lanka also suffered severe drought conditions. According to the National Oceanic and Atmospheric Administration (NOAA), the 1982/83 El Nino was estimated to have caused over USD 10 billion in damages due to floods, severe storms, droughts and fires around the world and over 2000 deaths. There was a mild ENSO event during 1986/87 and the effect on Sri Lanka was minimal. Since Sri Lanka is a comparatively small island, the ocean conditions around Sri Lanka can modify the El Nino effect. Therefore, the island's weather shows a different character compared to that in the Indian subcontinent.

Early this year, the meteorological indicators pointed to developing an El Nino and Sri Lanka received very little rain. However, according to the latest records, indications are that a mild El Nino will occur and hopefully the region will get back to normal weather conditions. Australia, one of the major agricultural producers, has recovered from drought although low rainfall persisted in some areas of New South Wales and Southern Queensland. In India normal rainfall is expected in the late monsoon period. China's Northern provinces are still in the grip of a drought although heavy rain has brought flooding to some parts of the south.

It is important to study about El Nino and related phenomena in order to predict unusual weather conditions affecting various parts of the world. In the event of an on-coming El Nino, these studies will help planners to decide on precautionary measures to be taken in agriculture, water management, and power generation. Scientists throughout the world are engaged in research trying to understand this earth science phenomenon. Sri Lankan scientists too must contribute to these efforts in all possible ways. Everyone will benefit if the character of El Nino is understood better because we all share one atmosphere. In Sri Lanka, targeted or directed research on El Nino is needed to understand the local level microscale factors that influence the large-scale character of the system. These micro-scale factors influence, among others, agriculture and the fisheries industry that have a heavy bearing on the country's economy. Therefore, it is also important to focus research towards understanding these factors and be able to predict the on-set of El Nino conditions in Sri Lanka.

W.L. Sumathipala 